American Journal of Applied Sciences 2 (10): 1471-1473, 2005

ISSN 1546-9239

(c) 2005 Science Publications

\title{
Chromium (III) Removal and Recovery from Tannery Wastewater by Precipitation Process
}

\author{
${ }^{1}$ Abass Esmaeili, ${ }^{2}$ Alireza Mesdaghi nia and ${ }^{1}$ Reza Vazirinejad \\ ${ }^{1}$ Department of Social Medicine, Rafsanjan University of Medical Sciences, Rafsanjan, Iran \\ ${ }^{2}$ Department of Environmental Health Engineering, Tehran University of Medical Sciences, Tehran, Iran
}

\begin{abstract}
Chromium (III) salts are the most widely used chemicals for tanning processes, but $60-70 \%$ of total chromium salts reacts with the hides. In the other word, about $30-40 \%$ of the chromium amount remains in the solids and liquid wastes (especially spent tanning solutions). Therefore, the removal and recovery of the chromium content of these wastewaters are necessary for environmental protection and economic reasons. Removal and recovery of chromium were carried out by using precipitation process. For this purpose, three precipitating agents calcium hydroxide, sodium hydroxide and magnesium oxide were used. The effects of $\mathrm{pH}$, stirring time, settling rate and sludge volume were studied in batch experiments. Results show that the optimum $\mathrm{pH}$ is 8-9 and the good sludge with high settling rate and lower volume obtain by the $\mathrm{MgO}$ precipitating agent. Hence the $\mathrm{MgO}$ is a good precipitating agent for removal and recovery of chromium from tanning wastewater.
\end{abstract}

Key words: Chromium, removal, recovery, precipitation, tannery wastewater

\section{INTRODUCTION}

Chromium solutions are widely used in many industrial processes such as chrome plating, wood preserving, textile dyeing, pigmenting, $\mathrm{Cr}$ chemical production, pulp and paper industrial and tanning. The wastewater resulting from these processes contains high amount of chromium metal which is harmful for the environment and human health ${ }^{[1,2]}$.

Tanning process using chromium compounds is one of the most common methods for processing of hides $^{[3]}$. In this process about $60 \%-70 \%$ of chromium reacts with the hides. In the other word, about 30\%$40 \%$ of the chromium amount remains in the solid and liquid wastes (especially spent tanning solutions). Hence, the wastewater of the tanning process is an important source adding $\mathrm{Cr}$ pollutant to the environment. In addition, the cost of the chromium metal is also important and it is possible to be recovered from the wastewatert ${ }^{[4-6]}$. Hafez et al. ${ }^{[7]}$ and Chaudry et al.$^{[8]}$ reported that the $\mathrm{Cr}$ ion concentration in the tanning wastewater varies from 2500 to $8000 \mathrm{ppm}$ and 1300 to $2500 \mathrm{ppm}$, respectively ${ }^{[7,8]}$.

Several methods have been used for removing toxic metal ions from aqueous solutions. These include chemical precipitation, ion exchange, reverse osmosis, membrane processes, evaporation, solvent extraction, and adsorption ${ }^{[1,4,5]}$. Of these, chemical precipitation is the usual way for this purpose. Many factors affect the process of chemical precipitation including the type of precipitation agent, $\mathrm{pH}$, velocity of precipitation, sludge volume, time of mixing and complexing agents ${ }^{[1,6,9]}$.
The purpose of this research was to compare $\mathrm{pH}$, velocity of precipitation, sludge volume, time of mixing and complexing agent when using the three precipitation agents (lime, sodium hydroxide and magnesium oxide) in the precipitation process of the tannery waste water chromium.

\section{MATERIALS AND METHODS}

The chemicals used in this research were raw wastewater from tanning process; solutions of lime, sodium hydroxide $15 \%$ and magnesium oxide $10 \%$. All chemicals used are of analytical reagent grade.

Since the process of tanning is batch, after finishing the process $(12 \mathrm{~h})$, spot samples were collected and transported to the laboratory for the determination of the most important parameters as quick as possible. These parameters include chromium concentration, $\mathrm{pH}$, total solids, dissolved solids, suspended solids, color, sulfate and chlorine concentration $^{[10]}$.

The jar test method has been used to determine the effect of each parameter, (six baker has been used for each stage) and $500 \mathrm{ml}$ of wastewater was added to each beaker. Precipitation agents were added to each sample separately and $\mathrm{pH}$ was controlled between 6 to 12 using nitric acid. In order to mixed solution, a sample was taken to the jar machine and samples were mixed for one minute in $90 \mathrm{RPM}$ as the first step. In the next step samples were mixed for 20 min with the speed of 30 RPM. After this $20 \mathrm{~min}$. Samples were taken out from the jar machine. In the last stage, after $4 \mathrm{~h}$ settling time, a sample was taken from the supernatant. Supernatant solution was then filtered and chromium concentration was determined.

Corresponding Author: A. Esmaeili, Rafsanjan University of Medical Sciences, Social Medicine Department. Rafsanjan, Iran, Tel: + 98391 5234003-5, Fax: +98 3915225209 
Table 1: Chemical analysis of tannery wastewater

\begin{tabular}{llllll}
\hline Parameter & Variation range & Average & Parameter & Variation range & Average \\
\hline COD $\left(\mathrm{mg} \mathrm{L}^{-1}\right)$ & $1850-2900$ & 2275 & color & Black green & - \\
T.S $\left(\mathrm{mg} \mathrm{L}^{-1}\right)$ & $76530-65440$ & 88650 & pH & 3.23 .7 & 3.5 \\
T.D $\left(\mathrm{mg} \mathrm{L}^{-1}\right)$ & $73050-94210$ & 86500 & Total Cr $\left(\mathrm{mg} \mathrm{L}^{-1}\right)$ & $3250-5300$ & 3950 \\
T.S.S $\left(\mathrm{mg} \mathrm{L}^{-1}\right)$ & & 2150 & Sulfate $\left(\mathrm{mg} \mathrm{L}^{-1}\right)$ & $2115-4250$ & 3525 \\
- & - & - & Chloride $\left(\mathrm{mg} \mathrm{L}^{-1}\right)$ & $18600-26700$ & 22070 \\
\hline
\end{tabular}

The effect of each factor on the three precipitation agents was measured by fixing the effect of the other variables. For instance settling rate, sludge volume and the shape of the precipitation for all precipitation agents were measured when $\mathrm{pH}$ was fixed at the optimum level. In order to determine the settling rate and sludge volumes, the samples were poured into scaled cylinders and after $5 \mathrm{~h}$ the height of supernatant or sludge volume was read. Atomic Absorption Spectroscopy method (Varian 975) was used for measuring chromium concentration in wastewater before and after settling process $^{[10]}$.

\section{RESULTS AND DISCUSSION}

The chracacterstics of the wastewaters are shown in Table 1. The average of chromium concentration in the raw wastewater of tannery process was $3950 \mathrm{ppm}$. The results of this study showed that the wastewater of tannery process is one the most important sources of environmental pollutants as the concentration of chromium and other harmful material in the wastewater is extremely high. This is also confirmed by many other studies $^{[11,12]}$.

The optimum $\mathrm{pH}$ for removing chromium from the tannery wastewater by sodium hydroxide and calcium hydroxide is shown in Fig. 1.

Figure 1 shows the minimum solution of chromium is presented at $\mathrm{pH} 8.5$ when using sodium hydroxide as the precipitating agent. In case of using calcium hydroxide as the precipitating agent, chromium concentration of settled wastewater decreased as $\mathrm{pH}$ increased. Increasing $\mathrm{pH}$ resulted in decreasing the chromium concentration in the supernatant. Although the optimum $\mathrm{pH}$ for $\mathrm{NaOH}$ was 8.5-9.5, the results showed when using $\mathrm{CA}(\mathrm{OH})_{2}$ as precipitation agent, increasing $\mathrm{pH}$ decreased the chromium concentration. This discrepancy can be due to the difference between the ability of the two precipitating agents for dissolving in water. This ability for $\mathrm{NaOH}$ is $100 \%$. Resulting chromium hydroxide from using $\mathrm{NaOH}$ has the most stability at the $\mathrm{pH}$ of 8.5-9.5. However adding more $\mathrm{NaOH}$ increases $\mathrm{pH}$ and this results in peptizing. In this situation, the chromium redissolve and therefore, the concentration of chromium in supernatant increases. In contrast, since the solubility of CA $(\mathrm{OH})_{2}$ is low, once a CA $(\mathrm{OH})_{2}$ is added to the wastewater $\mathrm{pH}$ increases and increasing $\mathrm{pH}$ results in peptizing. However, adsorption causes chromium ions take apart from the supernatant. Panswad et al. Reported that the optimum $\mathrm{pH}$ for $\mathrm{MgO}$ is $7-8^{[13]}$.

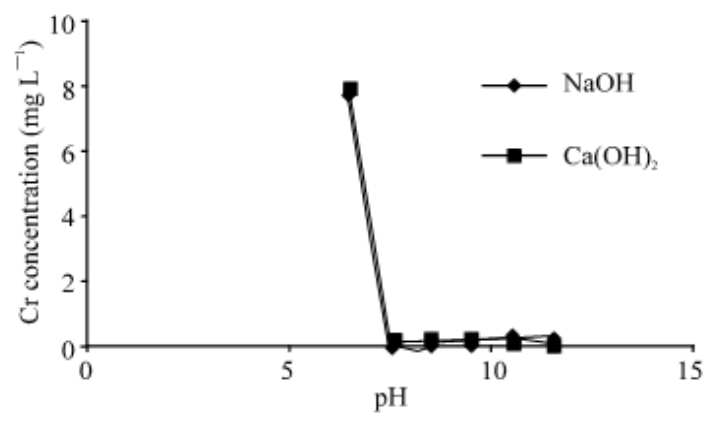

Fig. 1:Chromium concentration in suprnatant solution vs $\mathrm{pH}$ for sodium hydroxide and lime (after $4 \mathrm{~h}$ )

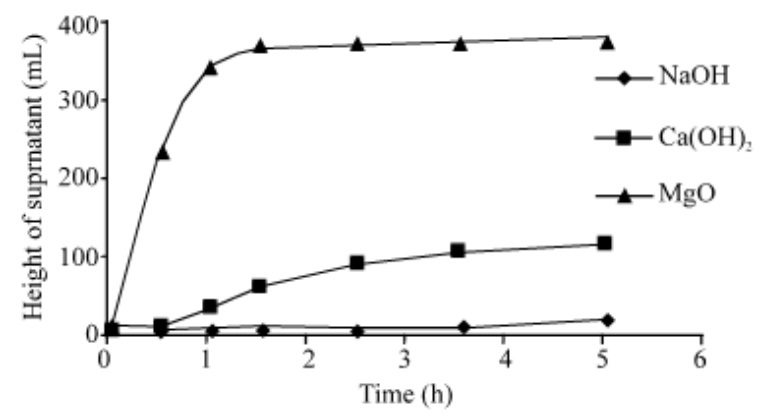

Fig. 2: Precipatation settling rate for three precipitation agents

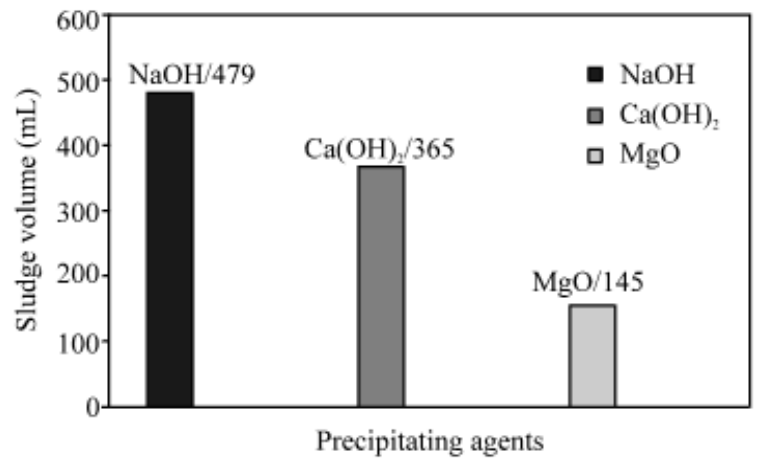

Fig. 3: Sludge volume for the three precipitation agents (settling time $5 \mathrm{~h}$ )

The settling rate for the three precipitating agents is shown in Fig. 2. The settling rate of the process for magnesium oxide is much more than this rate for the other two agents. Furthermore, a grainy, dense, easly setteable precipitate can also be formed when $\mathrm{MgO}$ is used as the precipitate. 


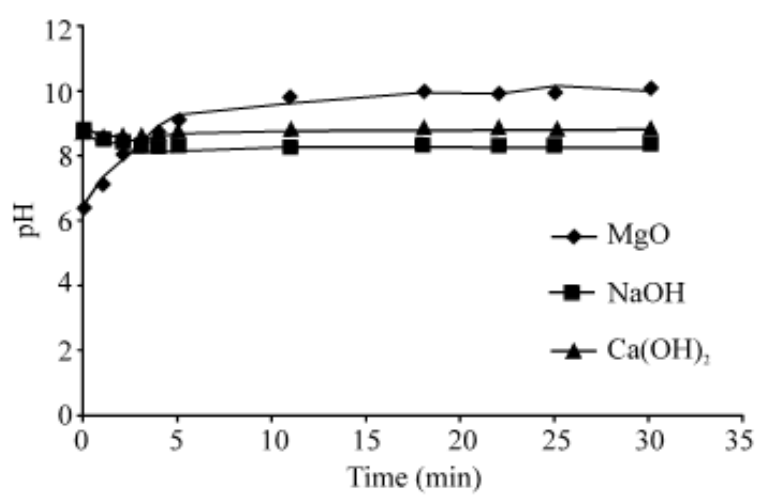

Fig. 4:Variation of $\mathrm{pH}$ vs mixing time for the three precipitating agents (velocity of mixing 90 RPM)

Whereas, precipitate forming from $\mathrm{NaOH}$ was very gelatinous and the settling rate was low. Sludges forming from $\mathrm{CA}(\mathrm{OH})_{2}$ was not also desirable. The results of the present study showed that high quality sludge, high settling rate and low volume of sludge was obtained by $\mathrm{MgO}$. Whereas, sludge forming from $\mathrm{NaOH}$ and $\mathrm{Ca}(\mathrm{OH})_{2}$ are very gelatinous. Furthermore, the settling rate for $\mathrm{NaOH}$ and $\mathrm{CA}(\mathrm{OH})_{2}$ is low and dewatering sludge is difficult. Similar to the results obtained by Panswad et al. and Hemming et al. ${ }^{[13,14]}$, our results showed that $\mathrm{MgO}$ is a suitable precipitating agent for removing and recovering chromium from tanning wastewater.

Figure 3 shows the sludge volume produced by the three precipitation agents. Sludge volume by $\mathrm{MgO}$ is much less than the sludge volume produced by CA $(\mathrm{OH})_{2}$ and $\mathrm{NaOH}$. The ratio of sludge is:

$\mathrm{V}_{\mathrm{MgO}}: \mathrm{V}_{\mathrm{Ca}(\mathrm{OH}) 2}: \mathrm{V}_{\mathrm{NaOH}}: 1: 2.5: 3.3$

As Fig. 3 shows the sludge volume of chromium hydroxide resulted from the $\mathrm{MgO}$ is also much smaller than this volume when using $\mathrm{NaOH}$ and $\mathrm{CA}(\mathrm{OH})_{2}$. This is important because not only helps to reduce the volume of the treatment plants, but also recovering chromium from such sludges is much easier than sludges with huge volume. The results of Panswad et al. confirm these results ${ }^{[13]}$.

An optimum time of rapid mixing for the three precipitation agents is shown in Fig. 4. The time needed for rapid mixing of $\mathrm{MgO}$ was longer than the other two precipitation agents.

\section{CONCLUSION}

It is concluded from our results that the optimum $\mathrm{pH}$ for the precipitating chromium from tannery wastewater is 8-9 and the good sludge with high settling rate and lower volume was obtained when using $\mathrm{MgO}$ as the precipitating agent. Hence the $\mathrm{MgO}$ is a good precipitating agent for removal and recovery of chromium from tanning wastewater. It is also concluded that magnesium oxide is much more desirable than lime and sodium hydroxide for removing and recovering chromium from tannery wastewater.

\section{ACKNOWLEDGEMENT}

The authors would like to thank Mr. Ghoshooni and Mr. Minasian for their cooperation.

\section{REFERENCES}

1. Patterson, J.W., 1985. Industrial wastewater treatment technology: Butter Worths: Boston.

2. Zayed, A.M. and N. Terry, 2003. Chromium in environment: Factors affecting biological remediation. Plant and Soil, 249: 139-156.

3. Sreeram, K.J. and T. Ramasami, 2003. Sustaining tanning process through conservation, recovery and better utilization of chromium. Resources, Conservation and Recycling, 81: 185-212.

4. Fabiani, C., F. Ruscio, M. Spadoni and M. Pizzichini, 1997. Chromium (III) salts recovery process from tannery wastewaters. Desalination., 10: 183-191.

5. Ludvik, J., 2000. Chrome balance in leather processing. United Nation Industrial Development Organization.

6. Kocaoba, S. and G. Akin, 2002. Removal and recovery of chromium and chromium speciation with MINTEQA2. Talenta, 57: 23-30.

7. Hafez, A.I., M.S. El-Manharawy and M.A. Khedr, 2002. RO membrane removal of unreacted chromium from spending tanning effluent. A pilotscale study, part 2. Desalination, 14: 237-242.

8. Ashraf Chaudry, M., S. Ahmad and M.T. Malik, 1998. Supported liquid membrane technique applicability for removal of chromium from tannery wastes. Waste Manag., 17: 211-218.

9. Tsugita, R.A. and R.H, Ellis, 1981. Pretreatment of industrial wastes manual of practice. WPCF No ED-3.

10. American Public Health Association, 1992. Standard Methods for the Examination of Water and Wastewater. 18th Ed. APHA, Washington DC.

11. Song, Z., C.J. Williams and R.G.J. Edyvean, 2000. Sedimentation of tannery wastewater. Water Res., 34: 2171-2176.

12. Ro, M. and A. Ganter, 1998. Possibilities of reduction of recipient loading of tannery wastewater in Slovenia. Water Sci. Technol., 3: 145-152.

13. Panswad, T., O. Chavalparit, Y. Sucharittham and S. Charoenwisedsin, 1995. A bench-scale study on chromium recovery from tanning wastewater. Water Sci. Technol., 3: 73-81.

14. Hemming, D., R.E. Hahn, J.R. Robinson and W. John, 1978. Recovery of chromium values from waste streams by the use of alkaline magnesium compounds. U.S. Patent 4108596. 